\title{
IDENTIFICAÇÃO DE ILHAS DE CALOR POR MEIO DE IMAGENS DE SENSORIAMENTO REMOTO E DADOS METEOROLÓGICOS DE SUPERÍFICE: ESTUDO DE CASO DE EVENTOS EXTREMOS NO VERÃO ATÍPICO 2013/2014 EM CAMPINAS-SP
}

\author{
Luiza Marchezan Bezerra ${ }^{(a)}$, Ana Maria Avila ${ }^{(b)}$ \\ (a) Geografia/Instituto de Geociências, Unicamp, luiza.bezerra04@gmail.com \\ (b) Centro de Pesquisas Meteorológicas e Climáticas Aplicadas à Agricultura (CEPAGRI), Unicamp, \\ avila@cpa.unicamp.br
}

\author{
Eixo: CLIMATOLOGIA EM DIFERENTES NÍVEIS ESCALARES: MUDANÇAS E \\ VARIABILIDADES
}

\begin{abstract}
Resumo
O verão 2013/2014 foi atípico na região Sudeste onde está localizado o município de Campinas. A falta de chuva elevou as temperaturas e as estações meteorológicas registraram os maiores valores para a época do ano. Este trabalho teve por objetivo o uso do satélite Landsat8 para a estimativa da temperatura de superfície e a identificação de ilhas de calor urbano em Campinas. Para a verificação dos valores obtidos por satélite, foi feita a comparação entre os dados estimados por este e dados de superfície. Foi aplicada a correlação de Pearson e os valores encontrados foram 0,49, 0,90 e 0,86, para as estações do Cepagri/Unicamp, do IAC e do aeroporto de Viracopos, respectivamente. $\mathrm{O}$ mapa térmico mostrou variação de aproximadamente $12^{\circ} \mathrm{C}$ entre as áreas urbanizadas e as áreas mais vegetadas, o que demonstra sensibilidade do sensor para captar a variabilidade espacial das temperaturas a superfície.
\end{abstract}

Palavras chave: ilhas de calor, sensoriamento remoto, clima urbano

\section{Introdução}

A formação de ilhas de calor nas grandes cidades está relacionada com o intenso processo de urbanização que se expande com a verticalização e o uso inadequado do solo (PEZZUTO, 2007), alterando a superfície e a atmosfera local favorecendo o aumento da absorção do fluxo de radiação solar. Como resultado das modificações da superfície e atmosfera local advindos das atividades antrópicas, este espaço urbano passa a ser composto por diferentes propriedades físicas e térmicas que atuam na geração de calor, na formação de resíduos e na modificação da rugosidade superficial (LOMBARDO, 1985). Com isto, o clima local sofre variações nas principais variáveis climáticas como temperatura, umidade, ventos e precipitação.

A série temporal de dados meteorológicos tem mostrado aumento nas temperaturas do ar nas últimas décadas em Campinas (BLAIN, 2010) e, uma das hipóteses é de que, este aumento pode estar relacionado com a expansão urbana do município que atualmente apresenta grau de urbanização de 98,28\% e 1.173.370 habitantes. Partindo-se da premissa que imagens termais podem representar informações 


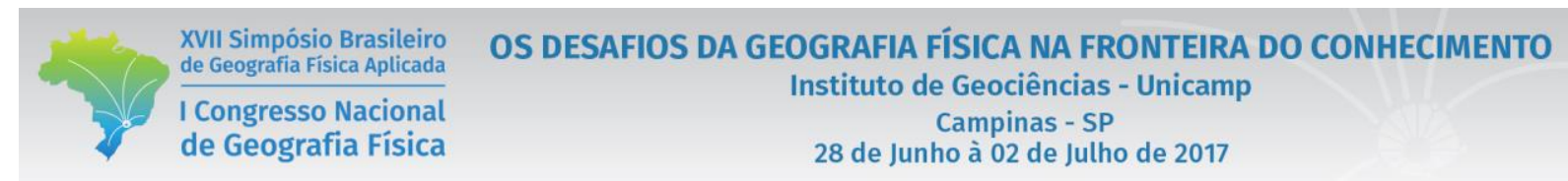

fidedignas da temperatura da superfície e que esta varia conforme o uso e ocupação do solo foram comparados os dados de imagens de satélite com dados de temperatura de estações meteorológicas disponíveis no município.

\section{Metodologia}

Foram utilizadas 17 imagens do sensor TIRS (Thermal Infrared Sensor), banda 10 e resolução espacial de 100 metros abordo do satélite Landsat8, entre 2013 e 2015 e dados de temperatura de três estações meteorológicas (Figura 1) do município em diferentes localizações: Centro de Pesquisas Meteorológicas e Climáticas Aplicadas à Agricultura (Cepagri), Instituto Agronômico de Campinas (IAC) e Aeroporto Internacional de Viracopos. Utilizou-se a correlação de Pearson à procura de uma conexão confiável entre os dados medidos no abrigo meteorológico a 1,5 metros de altura do solo e os dados de temperatura de superfície estimados pelo satélite. Posteriormente, foi confeccionado um mapa térmico da cidade de Campinas, com o objetivo de demonstrar a distribuição espacial da temperatura de superfície entre as estações analisadas.

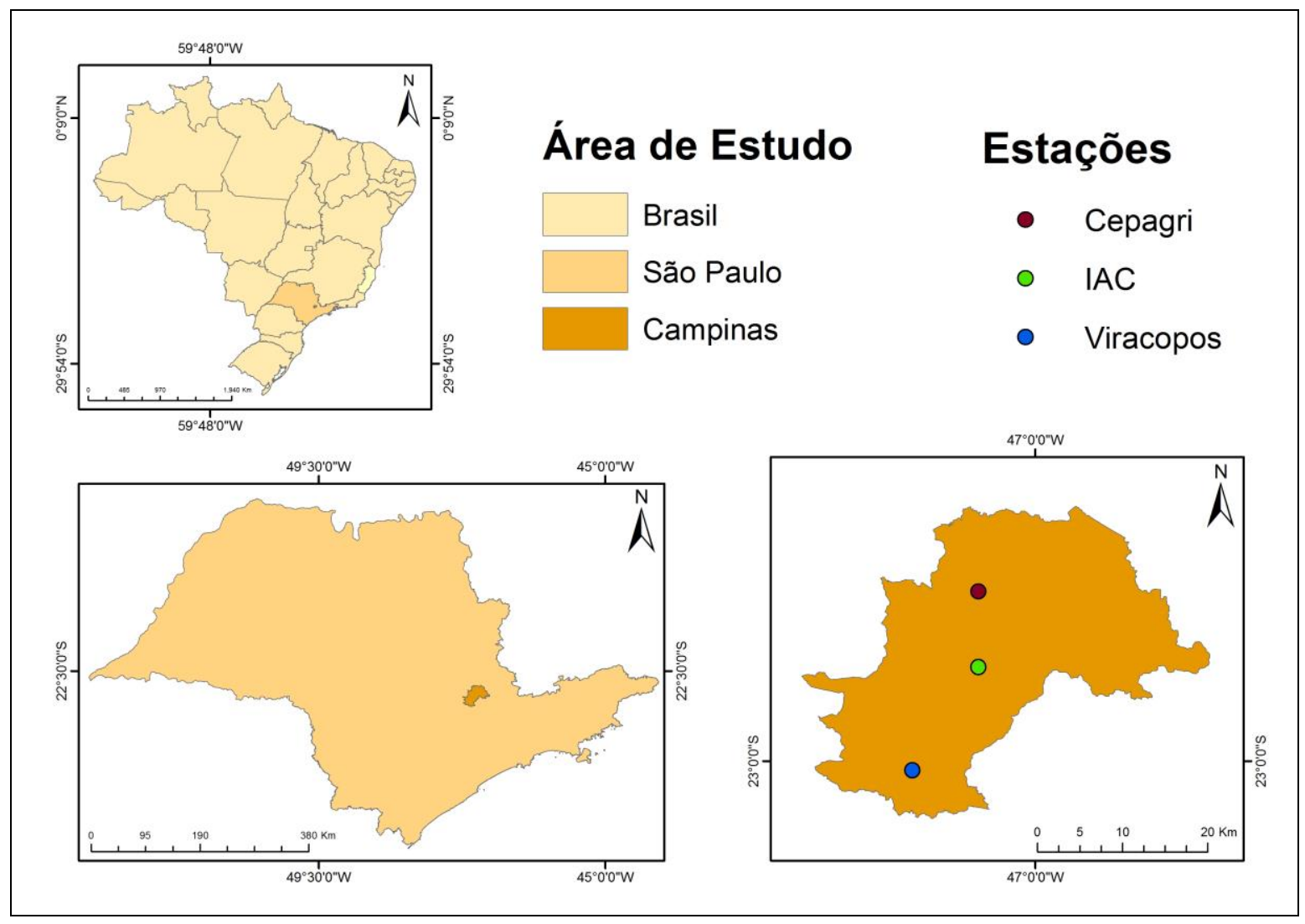

Figura 1. Localização das estações meteorológicas de Campinas 


\section{Resultados e Discussão}

Foi obtida uma correlação de 0,49 na estação Cepagri/Unicamp, 0,86 na estação do Instituto Agronômico de Campinas e 0,90 no Aeroporto Internacional de Viracopos. Os dados das estações do IAC e de Viracopos apresentam as maiores correlações com os dados de satélite, enquanto o valor da estação do Cepagri destoa. Tal fato pode ser explicado pelos distintos graus de urbanização onde se localizam as estações meteorológicas e pelas características heterogêneas da superfície local, como sua rugosidade, impermeabilidade, cobertura vegetal, concentração de edifícios e diferentes componentes presentes na atmosfera, como o vapor d'água. Essas características, segundo Voogt e Oke (2002), dificultam a aplicação dos sensores remotos para a estimativa da temperatura de superfície e suas correlações.

Mattar et al. (2012), em um trabalho para a estimativa de temperatura a superfície na cidade de Madrid, realizou experimentos com lançamento de balão meteorológico para análise do perfil vertical da atmosfera por meio da medição da concentração de aerossóis, velocidade do vento, umidade, pressão e temperatura, além da utilização de sensores de superfície para medir a temperatura na hora da passagem do satélite. Outra forma de verificar o padrão vertical da atmosfera é por meio de modelos numéricos mantendo os experimentos de campo com medidas em 3 diferentes pontos. No entanto, para a execução desses processos exigiria um grupo de pessoas envolvidas no processo, além de ferramentas e equipamentos onerosos.

O mapa térmico (Figura 2) mostra uma variação de aproximadamente $12^{\circ} \mathrm{C}$ entre as diferentes coberturas de superfície. Nas áreas vegetadas $34^{\circ} \mathrm{C}$ e $22^{\circ} \mathrm{C}$ nas áreas urbanas de maior temperatura. As temperaturas mais altas são caracterizadas pela cor vermelha e laranja escuro, e se concentram na região sul da cidade, onde se localiza a estação meteorológica do aeroporto de Viracopos. Nessa região, há o acúmulo de construções civis com materiais que favorecem a modificação do balanço radioativo em áreas com solo exposto e que podem ocasionar a redução da evapotranspiração e aumento do albedo. Esses fatores são responsáveis pelo aumento da absorção térmica da região, contribuindo para a elevação da temperatura.

Na porção oeste da cidade, onde se localiza a estação meteorológica do Cepagri, nota-se a predominância das cores mais claras, permitindo-se concluir que esta parte da cidade apresenta temperaturas mais amenas. É nesta região onde se localiza a Mata Santa Genebra, a segunda maior floresta urbana do Brasil, no qual é possível perceber a influência do clima urbano sobre ela através da sua tonalidade amarelada, já que os tons de verde seriam os mais apropriados para representar regiões com densa cobertura vegetal.

$\mathrm{Na}$ parte central da cidade, onde há a maior concentração de áreas impermeabilizadas, edificações, comércios e intenso tráfego de veículos, ocorre à transformação da rugosidade desta região que influencia na redução da velocidade média dos ventos regionais e no aumento da emissão de calor de origem 


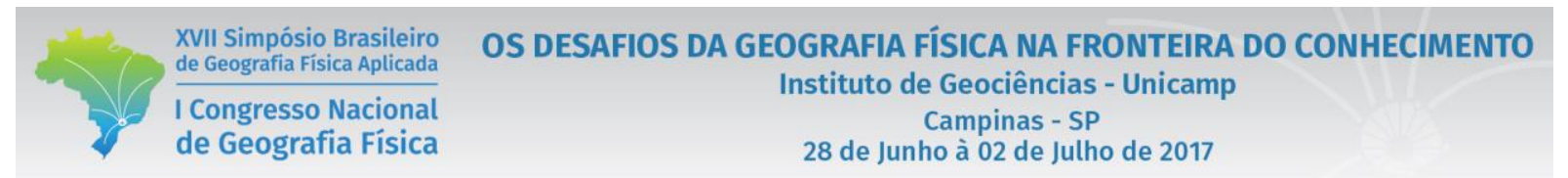

antrópica. É nesta região, caracterizado predominantemente pela cor laranja-escuro, que está localizada a estação meteorológica do Instituto Agronômico de Campinas.

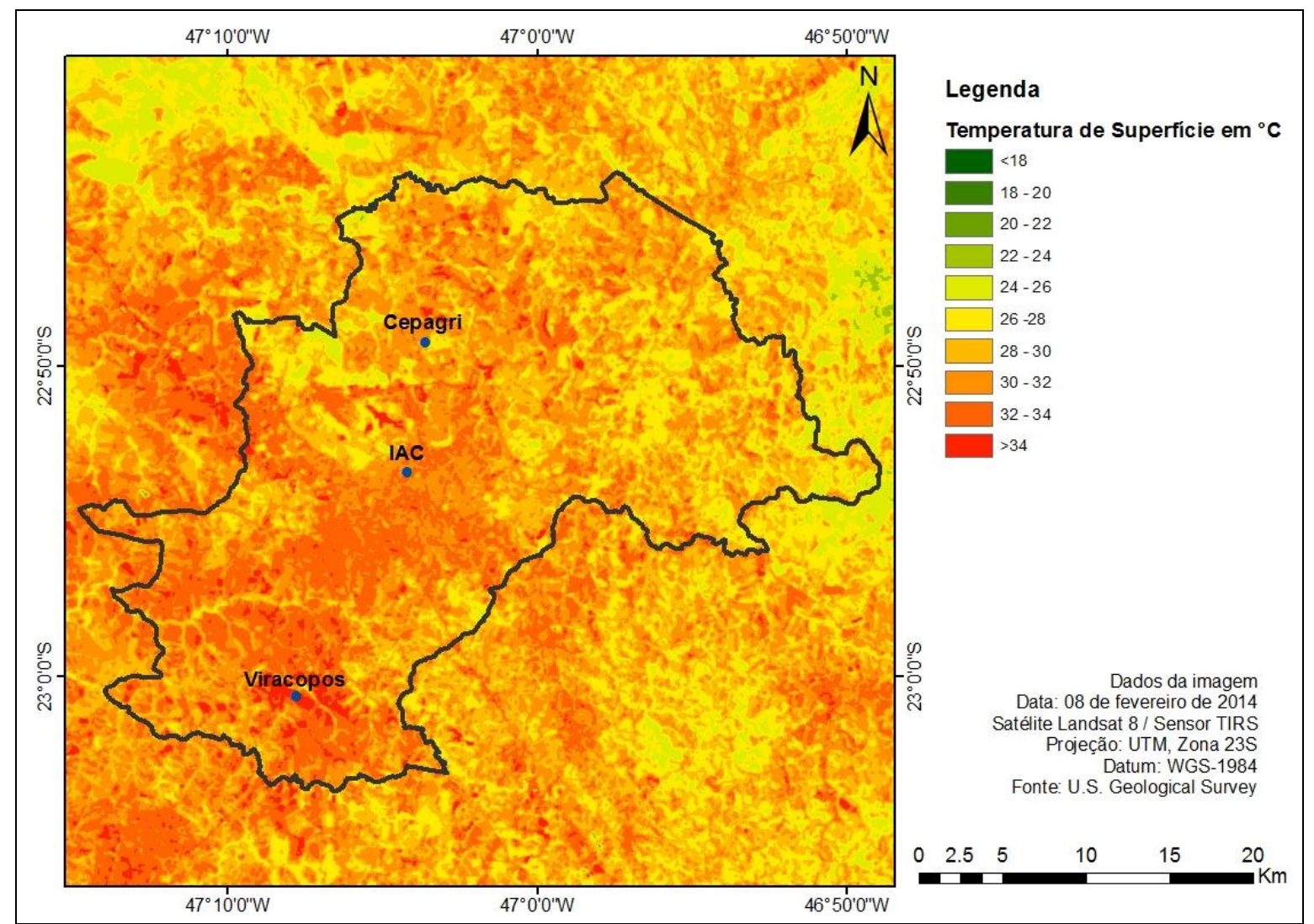

Figura 2. Distribuição espacial da temperatura de superfície no município de Campinas

\section{Considerações Finais}

O sensor TIRS do Landsat 8 mostrou-se eficiente para representar a variabilidade espacial da temperatura em áreas onde há pouca vegetação, conforme o tipo de uso e cobertura do solo encontrado na literatura.

Os desafios enfrentados durante estudos em clima urbano referem-se à heterogeneidade do ambiente físico e as atividades antrópicas que acabam por influenciar no clima local, conferindo às regiões analisadas caraterísticas singulares. Com isso, pode haver distorções na detecção dos valores dos alvos terrestres observados por sensores remotos, principalmente nos dados de temperatura de superfície.

Pesquisas mais aprofundada com sensores de temperatura de superfície juntamente com medidas de perfil vertical da atmosfera devem ser considerados em pesquisas futuras.

\section{Agradecimentos}

Agradeço à minha professora orientadora, Ana Avila, todo o suporte e confiança; e ao SAE pela oportunidade de desenvolvimento da bolsa de iniciação científica. 


\section{Referências Bibliográficas}

BLAIN, G.C. Detecção de tendências monótonas em séries mensais de precipitação pluvial do estado de São Paulo. Bragantina [online]. Vol.69, n.4, p.1027-1033, 2010.

LOMBARDo, M. A. Ilha de Calor nas Metrópoles: O Exemplo de São Paulo. São Paulo: Hucitec, 1985.

MATTAR, C. et al. Evaluation of the surface urban heat island effect in the city of Madrid by thermal remote sensing. International Journal of Remote Sensing, Madrid, v. 34, n. 9 -10, p. 3177-3192, out. 2012.

PEZZUTO, C. C. Avaliação do ambiente térmico nos espaços urbanos abertos. Estudo de caso em Campinas, SP. 2007. 182 f. Tese (Doutorado) - Faculdade de Engenharia Civil, Arquitetura e Urbanismo da Universidade Estadual de Campinas, Campinas, 2007.

VOOGT, J. A.; OKE, T. R. Thermal remote sensing of urban climates. Remote Sensing of Environment, Vancouver, v. 86, n. 3, p. 370-384, 2002. 